\title{
Operating Norms and Practices of Residents' Committees
}

The consequences and limits of management by numbers

\section{Wang Di}

Translator. Elizabeth Guill

\section{(2) OpenEdition}

\section{Journals}

Electronic version

URL: http://journals.openedition.org/chinaperspectives/6098

DOI: 10.4000/chinaperspectives.6098

ISSN: 1996-4617

\section{Publisher}

Centre d'étude français sur la Chine contemporaine

Printed version

Date of publication: 15 March 2013

Number of pages: 7-15

ISSN: 2070-3449

\section{Electronic reference}

Wang Di, "Operating Norms and Practices of Residents' Committees », China Perspectives [Online], 2013/1 | 2013, Online since 01 March 2013, connection on 28 October 2019. URL : http:// journals.openedition.org/chinaperspectives/6098; DOI : 10.4000/chinaperspectives.6098 


\title{
Operating Norms and Practices of
}

\section{Residents' Committees}

\author{
The consequences and limits of management by numbers
}

WANG DI

\begin{abstract}
This article, which is based on fieldwork carried out within a Residents' Committee in Beijing, explores the way in which this low-level urban society management authority functions. More precisely, it analyses the relationships established by these administrators with the higher echelons and likewise with the residents and the way in which these relationships develop, depending on the activities in question. It describes in particular how the expectations of the upper echelons, and the way in which they are expressed, orient and limit the practices adopted within these authorities and the operating norms that result. Particular attention is paid to the management by numbers imposed by the upper echelons, and its impact on the functioning of Neighbourhood Communities.
\end{abstract}

KEYWORDS: Residents' Committee, Subdistrict Office, management by numbers, norms, visibility.

F ollowing the reform of the work unit system begun in the late 1990s, groups officially qualified as "vulnerable" (ruoshi qunti 弱势群体) started to appear in urban society. Moreover, access to a certain number of public services and the implementation of official directives were entrusted to Neighbourhood Communities (shequ 社 区), increasing and complicating the administrative work they already undertook. If we add to these factors the development of internal migration, the extension of the area controlled by the Neighbourhood Communities, and the new heterogeneity of the population, it is not difficult to guess that ways of managing urban society underwent major transformations.

This article is based on an investigation carried out in the field between 2009 and 2011 in a neighbourhood of Beijing. It combined observation and participation as a trainee in a Neighbourhood Community and the authorities that comprise it. (1) The three grassroots authorities mentioned in this article are: the Party Committee of the Neighbourhood Community (dangwei 党委), the Residents' Committee or jumin weiyuanhui (juweihui 居委会) and the Neighbourhood Community's Workstation or gongzuozhan (工作站). Set up in 2007, the Workstations, which are executive bodies made up of employees paid by the Subdistrict Office (jiedao banshichu 街道办事处), are theoretically under the supervision of the Party Committee and the Residents' Committee placed at the head of the autonomous mass organisations known as Neighbourhood Communities. In reality, the Residents' Committee and the Workstation overlap considerably, and both are run by members of the Party Committee.

As a matter of fact, if we now examine the three grassroots authorities, the Party Committee, the Residents' Committee, and the Workstation, the first plays the role of director, orienting and controlling the activities of the two others. The Residents' Committee, officially an autonomous residents' organisation, theoretically has the function of listening to the aspirations of the residents and defending their interests, and deciding in a democratic manner on the work to be carried out by the Neighbourhood Community and exercising democratic control over its activities. The Workstation carries out the decisions of the Party Committee and the Residents' Committee. In theory, it is placed under the control of the Residents' Committee, but since its funding comes from the Subdistrict Office and all the Neighbourhood Community's employees are hired and paid by the Office, the aim of these various authorities is inevitably to serve the higher echelons of Party and state and to re-

I would like to thank Isabelle Thireau, Wang Hansheng, and Hua Linshan for the advice they gave me throughout my work in the field and during the writing of this article. I would like to thank Isabelle Thireau in particular for the corrections she suggested with a view to improving the content and translation. I alone remain, of course, responsible for the final content of the article. The research described in this article was co-financed by the Ministry of Education Fund for Youth Research into Human and Social Sciences (No. 12YJCZH193) and the Fund for assisting Chinese post-doctoral scientific research (No. 2012M510232)

1. The materials used in this study come from a survey carried out in the Neighbourhood Community of Minfengyuan and the Subdistrict Office of Fucai in the Gucheng District of Beijing. It is one of this Subdistrict Office's most extensive Communities, situated near the Second Ring Road and near a shopping area. Minfengyuan covers 0.25 square $\mathrm{km}$ and is the result of the merger, in 2000, of three Residents' Committees. The households on the Minfengyuan residence register number 2,441, representing 6,675 people. In 2009, there were 1,510 households of 5,285 people with permanent residence permits. This Neighbourhood Community has 7 hutong, 19 residential buildings (jumin lou), and 96 residents of single-storey houses (pingfangyuan). Its current residents are for the most part longstanding inhabitants. Compared to other more recent residential areas, it is representative of Beijing's traditional neighbourhoods. Names of people and places have been changed to preserve anonymity.

2. Between 2009 and 2011, the organisation of the Minfengyuan Neighbourhood Community in Beijing was as follows: the Party Committee and the Residents' Committee consisted of 11 people, theoretically elected by the members of the Party and by the residents. Amongst these 11 people, five were between 36 and 59 years old and educated to a level equivalent or superior to technical high school. They were employed full-time at Neighbourhood Community level; the Party Secretary was appointed by the Subdistrict Office (jiedao banshichu) and also carried out the duties of deputy head of the Residents' Committee. He was the main director of the political and administrative activities carried out within the Neighbourhood Community and the chief organiser of the work on a day-to-day basis. The six other people working within the Party Committee and the Residents' Committee were retired workers whose age varied between 56 and 74. These were residents who had not continued their education beyond the first stage of secondary school, and they did not participate in daily management tasks, but simply lent a hand when needed. Ten people worked within the Workstation, hired and paid by the Subdistrict Office. They were aged between 22 and 49 and were sometimes neighbourhood residents (in seven cases) and had studied to technological institute level or above (in seven cases also). Contrary to neighbourhoods made up of new, rather up-market housing where the owners' committees exercise an important influence on the Residents' Committees, those working within the Workstation were completely ordinary individuals, sometimes even from categories deemed vulnerable, such as the unemployed. Whether in terms of material conditions, social position, political power, or the resources at their disposal, these people tended to belong to the middle or lower ranks of society. Let us now consider the three basic authorities: the Party Committee, the Residents' Committee, and the Workstation. The first plays a managerial role, directing and controlling the activities of the two others. 
spond to demands from above, relegating the management of local affairs to second place. (2)

My fieldwork began in 2005 when I started to work as a volunteer, though on an irregular basis, participating in the activities of the Neighbourhood Community. I was able to observe a wide variety of work situations, collect documents, and conduct interviews. In particular, I collected all the local digital archives registered before the month of August 2008 and transcribed around 100,000 interview characters. From the end of 2008 to April 2009, I worked as a trainee, taking part in the management of daily affairs, the preparation of evaluations by the upper echelons, and in local elections. In late 2010, I helped with the sixth national census in Minfengyuan and in the course of this met the members of many households. This experience enabled me to gain an inside understanding of the way the Neighbourhood Community worked, the practices and perceptions of those who worked there, and the attitude of the residents, as well as enabling me to see which rules governed, according to circumstance, the individuals and groups concerned. (3)

In a previous publication, I presented one of the conclusions of this inquiry, showing how the management style exercised today by municipal and national governments through the administrative level of the Subdistrict Offices (jiedao banshichu) is essentially one of "management by numbers." (4) I will develop this perspective in this article by exploring the consequences of such "management by numbers" on the operating of the lower administrative Residents' Committees. Suffice is to say that "management by numbers" describes the fact that the official representatives of the town and neighbourhood do not administer the members of the Neighbourhood Community directly. They do not appear in the physical space or areas where concrete action takes place, but gather, analyse, and react to indicators drawn up for them and transmitted to them by the Residents' Committees through all manner of files, reports, tables, accounting grids, etc. It is through the intermediary of this statistical content that the relationship established between the authorities and urban society is now expressed. It is on this basis that the government has extended a process of "legalisation, normalisation, technicalisation, and standardisation" (5) to the most basic areas of local management, and has extended "the system of responsibility by objective" (6) (mubiao zerenzhi 目标责任制) and "the system of management by pressure" (7) (yalixing tizhi 压力型体制) to the management authorities of the Neighbourhood Communities. The latter, although not part of the official administrative and political hierarchy, have been placed under the direction of the Subdistrict Office and face new demands and injunctions from the upper echelons. They are also confronted, even though the demands of the two parties are not on an equal footing, with new expectations on the part of the inhabitants of the Neighbourhood Community.

As far as local residents are concerned, one point of view expressed in the current literature indicates that "the (official) demand for the participation of the inhabitants in certain of the Neighbourhood Community's affairs is aimed at obtaining their support for the political authorities and not at granting them rights, including them in the decision-making process, or developing their capacity to monitor and contain the public authorities." (8) Studies that express this opinion consequently agree upon the idea of "topdown" mobilisation. ${ }^{(9)}$ In doing so, they doubtless largely underestimate or ignore the possibility that residents may participate willingly in certain activities. A second point of view, however, describes the transformations that have taken place in methods of participation in public affairs in recent years, with "mobilisation" having given way to a type of "voluntary participation" that seems to have paved the way for the emergence of a new form of cit- izenship. ${ }^{10)}$ Research that adopts this point of view lists several forms of participation by residents ${ }^{(11)}$ and no longer considers them to be participat-

3. Alain Cottereau, "Dénis de justice, dénis de réalité: remarques sur la réalité sociale et sa dénégation" (Denial of justice, denial of reality: Remarks on social reality and its denial), in Pascale Gruson (dir.) and Delphine Dulong, L'Expérience du Déni: Bernard Mottez et le monde des sourds en débats (The experience of denial: Bernard Mottez and the deaf world), Paris, Éditions de la Maison des sciences de l'homme, 2000, pp. 159-178.

4. Wang Di, "Chengshi jiceng shehui de shuzihua shili (Management by numbers of grassroots urban society)," Hubei xingzheng xueyuan xuebao, No. 2, 2011, pp. 46-50.

5. Qu Jingdong, Zhou Feizhou, Ying Xing, "Cong zongti zhipei dao jishu zhili: Jiyu zhongguo 30nian gaige jingyan de shehuixue fenxi" (From macro-management to micro-management: Reflections on the Thirty Year Reform from a sociological point of view), Zhongguo shehui kexue, №. 6, 2009, pp. 104-127.

6. Wang Hansheng, Wang Yige, "Mubiao guanli zerenzhi: Nongcun jiceng zhengquan de shijian luoji" (Target management responsibility system:The practical logic of local party-state in rural China), Shehuixue yangui, No. 2, 2009, pp. 61-92.

7. Rong Jingben, Cui Zhiyuan, "Cong yalixing tizhi xiang minzhu heuo tizhi de zhuanbian: Xianxiang liangji zhengzhi tizhi gaige" (The move from a system based on pressure to a system based on democratic cooperation: The reform of governments at canton and district level), Beijing, Zhongyang bianyi chubanshe, 1998

8. Yang Min, "Gongmin canyu, qunzhong canyu yu shequ canyu (Citizen participation, mass participation and community participation)," Shehui, No. 5, 2005, pp. 78-95.

9. As for "mobilisation," see ideas on "mobilisation through participation" (Thomas P. Bernstein, "Stalinism, Famine, and Chinese Peasants: Grain Procurements During the great Leap Forward," Theory and Society, Vol. 13, No. 3, May 1984, pp. 1-38); "tactical mobilisation" (Ma Mingjie, "Quanli jingying yu jingyingshi dongyuan:Yige 'biminzhifu' de anli fenxi" [The exercise of power and mobilisation in exercise: a case of "Bimin Zhifu"], Qinghua shehuixue pinglun, No. 1, Xiamen, Lujiang Press, 2000, pp. 47-79), as well as other types of mobilisation such as "mobilisation through participation, occasional movement, and organised mobilisation" (Sun Liping et al., Dongyuan yu canyu: Disan bumen mujuan jizhi ge'an yanjiu [Mobilisation and participation: A case study on the mechanism of third sector endowment], Hangzhou, Zhejiang Renmin Chubanshe, 1999), "forced and united mobilisation" (Wang Sibin, "Lun minbenzhuyi de shequ fazhanguan" [On the development of the Neighbourhood Community founded on the Minbenzhuyi concept], Shehui kexue, No. 1, 2001, pp. 34-38), and "the method of mobilisation by the State, the method of mobilisation by the élite," (Yang Min, "Gongmin canyu, qunzhong canyu yu shequ canyu [Citizen participation, mass participation and community participation]," Shehui, No. 5, 2005, pp. 78-95). See also research on techniques of mobilisation such as the "complaint" (Guo Yuhua, Sun Liping, "Suku: Yizhong nongmin guojia guannian de xingcheng jizhi" [Accounts of bitterness: Mechanism of the shaping of the idea of state amongst peasants], Zhongguo xueshu, No. 4, 2002), "the creation of models" (Feng Shizheng, "Dianxing:Yige zhengzhi shehuixue de yanjiu" [The model: a study of political sociology], Xuehai, No. 3, 2003, pp. 124-128) and "ceremonialisation" (Guo Yuhua [ed.], Yishi yu shehui bianqian [The rite and social change], Beijing, Shehui kexue wenxian chubanshe, 2000).

10. Zhou Zhijia, "Huanjing baohu, qunti yali haishi liyiboji" (Protection of the environment, group pressure or interests relatedness?), Shehui, No. 1, 2011, pp. 1-34.

11. See research on the participation of the inhabitants as the "participation in well-being, participation in leisure activities, participation through self-interest" (Yang Min, "Zuowei guojia zhili danyuan de shequ: Dui chengshi shequ jianshe yundong guochengzhong jumin shequ canyu he shequ renzhi de ge'an yanjiu" [Community as state governance unit: A case study on residents' community participation and cognition in the process of community building campaign], Shehuixue yanjiu, No. 4, 2007, pp. 137-164), on "the factors of resistance, factors leading to the expression of interests, those inciting participation in elections" (Hu Rong, "Shehui ziben yu chengshi jumin de zhengzhi canyu" [The social capital and political participation of urban residents], Shehuixue yanjiu, No. 5, 2008, pp. 142-159), as well as that on ideas of "participation linked to a demand for information or assistance" (Zhou Zhijia, "Huanjing baohu, qunti yali haishi liyiboji" [Environmental protection, group pressure or interests relatedness?], Shehui, No. 1, 2011, pp. 134), or "participation to obtain the means to live, participation for the defence of rights and responsibilities" (Wang Xing, "Liyi fenhua yu jumincanyu: Zhuanxingqi zhongguo chengshi jiceng shehui guanli de kunjing jiqi lilun zhuanxiang" [Interests differentiation and residents' participation: The dilemma and theoretical transition of China's urban grass-roots social management], Shehuixue yanjiu, No. 2, 2012, pp. 20-34). Luigi Tomba has shown in several articles how the various forms of participation are in reality closely linked to the differentiation and stratification of the social structure in China ("Creating an Urban Middle Class: Social Engineering in Beijing," The China Journal, No. 51, 2004, pp. 1-26; "Of Quality, Harmony, and Community: Civilization and the Middle Class in Urban China," Positions: East Asia cultures critique, Vol. 17, No. 3, 2009, pp. 592616; "The Housing Effect: the Making of China's Social Distinctions," in C. Li (ed.), China's Emerging Middle Class: Beyond Economic Transformation, Washington, DC, Brookings Institution Press, 2010, pp. 193-216). To this research may be added, in a transnational comparative perspective: Sidney Verba, Norman Nie, and Jae-on Kim, Participation and Political Equality: A Seven Nation Comparison, New York, Cambridge University Press, 1978, and the many publications of Benjamin L. Read showing how the capacity for participation and the democratic conscience of civil organisations can, to a certain extent, restrain political authority ("Revitalizing the State's Urban 'Nerve Tips,"' The China Quarterly, No. 163, 2000, pp. 806-820; "Democratizing the Neighbourhood? New Private Housing and Homeowner self-organisation in Urban China," The China Journal, No. 49, January 2007, pp. 31-59; "Assessing Variation in Civil Society Organisations: China's Homeowner Associations in Comparative Perspective," Comparative Political Studies, Vol. 41, No. 9, 2008, pp. 1240-1265). 
ing passively in any kind of state-generated mobilisation. On the contrary, it depicts them as capable of exercising influence on others through intentional, strategic action. Such approaches highlight the demands of the inhabitants, their participation in community affairs, and the various factors that motivate them.

The configuration ${ }^{(12)}$ in which the three main authorities, the Party Committee, the Residents' Committee, and the Workstation, appear is therefore the following: top-down administration by numbers, a system of responsibility by objective, a system where pressure dominates, and the capacity of individuals to take initiative, even though the methods of participation and the demands of the residents are analysed in a variable manner by the literature. How, therefore, does this configuration steer the daily work of the Residents' Committees? What internal operating methods do they adopt and to what extent do these gradually result in the shaping of norms and shared principles? These are the questions this article will attempt to answer by analysing different working situations.

\section{Control by numbers and the importance of documentation techniques}

According to Michel Foucault, the exercise of social surveillance and control generally leads to the setting up of the following system: through a whole series of files and detailed directives, individuals and activities are schematised in one form or another in order to be described, analysed, measured, compared, and classified for all sorts of uses intended to further the pursuit of various objectives. ${ }^{(13)}$ So it is with the Subdistrict Office and the upper echelons who now exercise control over residents and the work done by the lesser urban society authorities through the allocation of a certain number of points to all sorts of objects, individuals, and management and control tasks. This gives them a means of objectifying, assessing, and checking on activities that form part of the daily administrative workload but are difficult to evaluate. It is this control system that directs the daily work of the Residents' Committee as well as that of other departments responsible for effectively implementing the policies that have been adopted. For example, the Committees make distinctions between activities that can be quantified, and which concentrate their attention because they are the subject of stricter checks by the upper echelons, and activities that are not subjected to a process of quantification, and which are therefore carried out in a more flexible manner or even completely ignored.

\section{The effects of control by numbers in the face of an indifferent population}

Let us take an example to illustrate this point. In mid-November 2011 the administrators of the Minfengyuan Neighbourhood Community in Beijing were warned that two experimental projects entitled "Building Residents' Committees Directed Towards Study" and "Constructing Places that Testify to the Progressive Nature of the Party's Grass-roots Organisations" were to be evaluated, and what's more, at almost the same time. Just before the evaluation of the first project, the higher authorities sent them a series of documents and tables to fill in with the aim of identifying, accounting for, and measuring the efforts made. "Building Residents' Committees Directed Towards Studies," a project concerning the cultural activities offered to residents, was by definition difficult to analyse and evaluate. For the pur- poses of the evaluation it was therefore translated into a series of concrete quantification systems. The same process was repeated to identify and evaluate the "Party's Progressive Organisations."

The work of the team responsible for the evaluation was composed of three elements:

1) listening to the reports of the Secretary of the Party Committee, the Deputy Head of the Neighbourhood Community's Residents' Committee, and others on the activities carried out,

2) consulting the documents, archives, and tables demonstrating the attention effectively paid to residents' training and the reinforcement of the progressive nature of the Party Committee, and

3) carrying out an on-site check of the facilities and equipment designed to support these activities, such as a cultural activities centre, classrooms, textbooks, and other items reflecting the investment made.

However, everybody knew that the teams in charge of these evaluations favoured the first two elements. In other words, they were above all interested in documents and files, in particular those with figures, either explained orally or that could be consulted on-site, and they checked to see if they had been filled in correctly, that is to say, that no sections were missing. On the other hand, their members devoted little time to the observation of facilities and other material objects used in the activities under evaluation. Moreover, since they did not have the means to verify what, if anything, had been accomplished, they limited themselves in general to casting an eye over the study or training programs on offer on the day of their visit to the Residents' Committee's activity centre.

Such activities, whether cultural activities offered daily by the Residents' Committee or those taking place on the day of the evaluation, are impossible to organise without the participation of local residents. However, the way in which residents participate in the cultural arena presents certain particularities. Indeed, there is no evidence here of any form of participation that highlights, perhaps in the shape of a demand, people's rights or expresses any particular requests. Neither can we see any form of participation based simply on the residents' dependence on the Committee, that is to say on advantages the former might derive from the latter: the activities on offer do not really present any particular appeal in terms of social assistance or quality of entertainment. The participation of the residents here is more likely to be characterised by indifference or lack of involvement.

"Who wouldn't prefer to relax quietly at home? But they make you sign up to join them, so what can you do? It's not easy for them either. And then, you can always avoid seeing them by walking head down in the street, but the day you look up you can be sure you'll bump into one of them. So if you can give them a helping hand...." this was the point of view expressed by several residents asked to take part in these activities. The interviewee mentioned above continued, with regard to the activities concerned, "It's

12. In his major work on the aristocracy published in German in 1969 and translated into English in 1983 by Edmund Jephcott under the title The Court Society (New York, Pantheon Books), Norbert Elias described the words and actions that display the intentions and strategies of individuals and the interdependent relationships that exist between them. To explain these interactions, he uses the term "figuration." Certain researchers, including us in this article, assimilate the idea of "configuration" with that of "figuration" (Tânia Quintaneiro, "The Concept of Figuration or Configuration in Norbert Elias' Sociological Theory," Teoria \& Sociedade, No. 2, 2006). They consider this idea to be a form of special interdependence between individuals and a physiognomy of the social communication network.

13. Michel Foucault, Surveiller et Punir (Discipline and punish), translated by Liu Beicheng, Yang Yuanying, Beijing, Sanlian Press, 2003, pp. 208-216. 
always the same thing, but they tell you to come so you come; we don't expect much...." (14) This attitude reveals two important pieces of information for those who run the Neighbourhood Community: residents are ready to collaborate, since they know they cannot avoid meeting them one day or another, but the content and quality of the activities offered mean little to them.

The members of the Subdistrict Office and the upper echelons of the administration, as well as the residents, are therefore in agreement on one point: they are not really concerned about the activities in themselves. So the various organisations of the Neighbourhood Community can concentrate their efforts on the documents and files to be filled in and on the various ways of clearly depicting how their activities are organised and the positive outcomes of the tasks undertaken.

\section{Giving visible shape to what must be seen}

For example, after receiving the evaluation grids to fill in for the project "Building Residents' Committees Directed towards Study," the members of the Minfengyuan Neighbourhood Community devoted 17 and 18 November 2011 to completing files where the required information was missing and preparing tables, diagrams, photo panels, and Power Point displays to back up oral presentations. Everything done to complete the existing data was done using officially recognised, familiar, legitimate techniques of rendering a certain reality visible. The members of the Neighbourhood Community therefore embarked on various operations involved in the "constitution of the visible," to use Olivier Voirol's expression, ${ }^{(15)}$ and which were linked to a greater or lesser degree to reality.

For example, the information to be filled in concerning the content of the "training given to people who have lost their jobs or are unemployed and workers coming from outside" was glaringly absent in Minfengyuan. The staff concerned therefore chose to use photos taken during other, older activities and to order them by month, dating them and adding a few notes. The work of making up a file was carried out with great attention to detail, taking account of the information contained in the photos (for example, the clothes people were wearing), to determine at what time of year they had been taken and which month could be assigned to them. New captions were created. A photo showing a gathering in the conference room was recaptioned "Organisation of a New Year meeting with workers from outside the area to gain an understanding of their training needs" so it could be included in the file that had been prepared. In order not to arouse suspicion, the calendar was frequently consulted to ensure that activities were not claimed to have taken place on a Saturday or Sunday or during an official holiday.

Besides this attention to detail, great attention was paid to form. When the two joint evaluations mentioned above were to take place, the head of the Residents' Committee and the Secretary of the Party Committee drew on all sorts of resources to improve the presentation and aesthetic quality of the documents and material to be exhibited and made a Power Point presentation to support the oral reports. The head of the Residents' Committee requested the use of the conference room and the Subdistrict Office's computer for its presentation. The Party Secretary requested help from a public work unit with offices in the area administered by the Neighbourhood Community so that all the documents and materials could be printed in colour. He also turned to a national museum to borrow a laptop computer and projector. A white sheet was hung in the conference room of the
Residents' Committee as a screen for projecting the Power Point presentation and photographs illustrating the Committee's activities. The aim of these procedures during the evaluation exercise was to give as physical and visible a form as possible to the official criteria, thereby demonstrating the success of the work undertaken.

Besides the requirement for visibility enshrined in the type of data needed for the evaluation, it was also necessary to demonstrate an essential element of this exercise, that is to say, the participation of the residents. By telephoning residents or knocking on their doors, the members of the Committee called on those who had benefited from various forms of social assistance in the past (minimum living wage, payment for voluntary work, compensation for the families of handicapped soldiers), asking them to be present in the activity room during the evaluation team's visit, playing cards or chess, taking part in group singing, painting, or reading in the library, in order to create the atmosphere of a community of residents interested in study, training, and cultural activities.

Thanks to a whole series of discrete, intense preparations, the two evaluation days of 19 November (for the "Building Residents' Committees Directed Towards Study" project) and 27 November (for the "Building Places to Demonstrate the Progressive Nature of Grass-roots Party Organisations" project) ran very smoothly. The tables, grids, and documents were the object of detailed analysis and were approved by the administrators from the upper echelons. The atmosphere in the Residents' Committee conference room and the presence of residents and members of the Party were judged positive. Thanks to the variety of processes involved in creating various forms of visibility, a "concrete, tangible, and demonstrable" reality was constructed. ${ }^{(16)}$ This became the object of description and judgments. During this process, recourse to different techniques of documentation and communication played a dominant role, supplemented by the mobilisation of residents and locally accessible resources.

\section{The management of the population through numbers and the transformation of the individual into a numeric character}

The injunctions but absence of direct intervention on the part of the upper echelons of Party and state administrators in the work of the lower-level authorities, and the passive participation or lack of general interest on the part of the residents, nonetheless influence the work done outside these formal periods of evaluation. For example, daily management work is also influenced by the nature, both asymmetrical and indirect, of the relationships established between the Residents' Committee and the two other parties involved: the Subdistrict Office and the residents themselves. ${ }^{(17)}$ The result is an extended decision-making area for defining ordinary operating practices, which in turn influences the norms and internal regulations that gradually prevail. Let us take the example of management of the urban population.

Today, although technology is more advanced and the information contained in the files more complete than previously, it is no longer a question

14. Conversation with a resident named Wang Ruixuan, Beijing, 4 January 2009.

15. Olivier Voirol, "Presentation, visibility and invisibility: An introduction," Réseaux, Vol. 129-130, No. 1, 2005, pp. 9-36 (DOI : 10.3917/res.129.0009).

16. Olivier Voirol, op. cit

17. Giuseppe Manno has explored in particular the consequences of these indirect relationships or "indirection": Giuseppe Manno, "La politesse et l'indirection: un essai de synthèse (Politeness and indirection: a summary), Langage et société, Vol. 100, No. 2, 2002, pp. 5-47. 
of grassroots authorities overseeing and exercising total, strict, and permanent control over individuals and their actions within a closed, circumscribed area. The area administered by these authorities has, in fact, grown, as in the case of the Fucai Subdistrict Office in the Gucheng District of Beijing. In the early 1980s, it controlled 68 Residents' Committees. Following a succession of regroupings and redeployments, it now presides over the affairs of 19 Committees, which means that the area run by the Neighbourhood Communities has been enlarged three-fold on average. Consequently, the new tasks demanded by the upper echelons and the problems to be solved now concern a far wider population that is both complex and fluctuating, which makes the situation far more difficult than it was 30 years ago. The management of the migrant population poses specific problems. Lastly, methods of mobilisation and the ways in which the population participates have changed, and this, combined with the extension of the area under administration and the mobility of the population, has resulted in changes in forms of sociability and relationships between neighbours. Situations that were unknown yesterday have emerged, such as residents not knowing their neighbours. Mistrust of outsiders is widespread. In addition, a decreased feeling of belonging to a district and the structures that govern it, coupled with the weakening of neighbourhood relationships, has reinforced the limited, passive participation of most residents in population management matters. However, in matters of population management, what interests the Subdistrict Office and the higher authorities is essentially figures and demographic indicators, without any real attention being paid to the concrete effects of new forms of mobility. For their part, residents seem fairly indifferent to population management issues. Consequently, the members of the lower authorities have more room to manoeuvre and an extended area of decision-making, which has led to the emergence of shared operational norms, such as those known internally as "reshuffling the figures" (shan shu 删数) or "borrowing the figures" (jie shu 借数).

\section{"Reshuffling the figures": The example of management of the urban population}

In 2007, to guarantee security for the approaching Olympic Games, the Fucai Subdistrict Office in Beijing's Gucheng District appointed a migrant population manager to each Workstation, all placed under the direct authority of the Office's migrant population management office. At the end of 2007, the newly-appointed manager in charge of this task in the Minfengyuan Neighbourhood Community had devoted more than a month to estimating the number of local migrants. He arrived at a figure of 2,600 people, and this was reported to the upper echelons and included in the official joint database.

From 13 March to 13 April 2009, the authorities for the district demanded that more detailed information on this population be consigned to the database, such as the number of household members that had stayed in their native place, the name of the head of household, and the jobs held by the household's members. In mid-April, a check on the quality of the additional information was announced. Two Subdistrict Offices were chosen in a random draw, then two Communities in each Office were likewise picked out in a draw, and the same procedure was followed for 25 of the files in each of the Communities. To pass this check, 97 percent of the information requested had to be correctly filled in. However, the Offices had increased the percentage to be reached in order to ensure the success of the enterprise. They also drew up a scale of sanctions: a fine of 50 yuan would be deducted from the salary of the manager concerned for a single incomplete individual migrant file, rising to 200 yuan for two incomplete files, with dismissal in the case of three incomplete files.

The staff of the Neighbourhood Community were powerless to change these decisions. Yet the total migrant population in Minfengyuan was still that which had been officially declared in 2007 , i.e. 2,600 people. Replying to the very detailed questions posed for such a large number of people was daunting. Faced with an objective that seemed impossible to achieve, the managers of each Community therefore undertook to "reshuffle the figures," an expression that described not some vague, one-off activity, but a clearlyestablished working norm. One of them told me:

Together with a colleague, over several successive Tuesdays, when access to the common database was open in the morning, we "reshuffled the figures," removing several hundred migrants on each occasion. In the end, we were left with around 1,000. We had to stop because an order suddenly came from above that we were no longer allowed to "reshuffle." It's true that each Community did the same thing and that in the end the figures were too divergent from the official figures. But we did what we could, when we could. If we had been picked in the draw, it would simply have been a question of "bad luck!" (18)

These "reshuffled figures" are still clearly visible today if we consult the "Final Report on the Management of Housing Rental and the Migrant Population in the Fucai Subdistrict Office."

Between 1 February 2009 and 3 July 2009, the migrant population reached 14,147 . Since then, new information requested on migrants has been provided for 2,763 people. The information was then modified in 1,276 of the files. The number of people whose files were cancelled numbered 10, 108. (19)

In each Community, the managers ensured the disappearance of most of the migrants previously declared.

Individuals therefore became mere numbers, of interest only on account of the quantification process they facilitated. This process, which led to a weakening of any real capacity to manage urban areas, was used by the managers concerned in response to controls by the higher authorities, who exercised power through a random draw and a punishing scale of sanctions. "Reshuffling the figures" was quite simply a question of reducing the work required so that the tasks demanded became accessible and doable.

\section{"Borrowing the figures": The example of the national census}

During the sixth national census, other situations of the same kind occurred when the attention of the higher authorities was directed solely towards the figures registered by the lower authorities, without any real control of the processes by which the figures were collected. The residents, who had been the target of a long campaign of information and propa-

18. Interview with Wu Hongtian (migrant population manager in the Neighbourhood Community of Minfengyuan), Beijing, 18 March 2009

19. "Final Report on the work of managing housing rental and the migrant population in the Fucai Subdistrict Office," Beijing, 10 November 2009. 
ganda, displayed a certain degree of enthusiasm for collaborating in the census work, but without attaching any particular importance to the accuracy and truth of the facts that were recorded. Faced with this situation, the staff of the Neighbourhood Community chose an unusual modus operandi whereby correctly filling in the existing sections was more important than the accuracy of the information. In other words, the real work of the census was above all governed by the need to provide the required indicators.

From 15 August to 15 September 2010, the members of the Workstation and other employees of the various departments of our Neighbourhood Community carried out the work of ordering and updating family situations. The work was carried out with varying degrees of attention to detail depending on the area, the objective being to prepare "registers of heads of household with family and first names" that were as reliable as possible in view of the national census that was to take place in November (the different stages of the latter are described in Table 1). In Minfengyuan, the updating of these registers was done not by recording the information gathered in August and September in reply to questions such as "how many people are there in the household?" or "which members declared as being part of this household do not live there?", but by recopying information from five documents held at the police station. The documents in question were: 1) a file on those people in possession of a residence permit, 2) a file containing the names of residents whose residence permits were elsewhere (you ren wu hu 有人无户) or who should have registered their permit in a particular place but had not yet done so, 3) a table summarising the number of holders of a provisional residence permit, 4) a document including the registration files of the above holders in the police station, and 5) a list of foreigners. To these documents were added the data contained in two other police files, the first containing information on births and deaths, and the second recording departures and arrivals in the neighbourhood. It was therefore considered preferable that the basic data for the national census should match other official data rather than the reality. (see Table 1)

Although this work was partly biased in Minfengyuan due to the use of official data held at the police station as the starting-point of the census, it is nonetheless true that the surveys carried out among households between 1 and 10 November revealed several major changes in the population. Moreover, the information gathered in the census supplemented and corrected the police data. Finally, on 15 November, figures concerning the number of individuals with or without a residence permit in the neighbourhood were sent to the Subdistrict Office in Gucheng District.

From the moment these figures were established in this way, the data concerning the Minfengyuan Neighbourhood Community could not be altered. Consequently, when mistakes were discovered between 16 and 25 November, that is to say, in the course of the two final stages of the census, they could not be integrated into the official data. The staff concerned had to resort to the practice known as "borrowing figures" to remedy the differences that had come to light. For example, the district's census zone 14, which had made a mistake in the number of households in a certain category - it had counted one too many - preferred, rather than revising all the figures for the zone, to "dismantle a household" (chai hu 拆户) from census zone 11, which was late with its count, and transform one of the latter's "collective households" into two households, one of which it transferred to zone 14 to correspond to the official figures. (20)

These practices of "reshuffling the figures" and "borrowing figures" confirm that with the increase in the Chinese population, its increasingly di- versified composition, and the development of internal migration flows, the work of population management by the state is increasingly done through a process of standardisation and the resulting specific control activities, in particular, the setting up of an increasingly intrusive system of sanctions, both positive (bonuses, promotion) and negative (censure, absence of bonuses, job changes), to channel the work required. This standardisation goes hand-in-hand with a fairly high disregard for the actual situations encountered and the inability of the authorities to control the accuracy of the data provided. Consequently, those working in the grassroots authorities mainly respond to specific requirements by shuffling the figures. These figures, and the tables drawn up using them, have become the main method of interaction between the higher and lower administrative levels. The individuals that make up the population and the households in which they live have become numerical symbols that may be used, as required, in addition, subtraction, correction, and dismantling operations.

\section{Administrative work "by numbers" and the influence of the attitude of local residents}

Whether during the occasional evaluations by the upper echelons or in the daily management of the population, most, if not all, local residents express limited support for these operations and participate only passively. These activities have little impact on their daily lives, at least in the situation I was able to observe in Minfengyuan. Those who work in the Neighbourhood Community have above all to cope with the demands and directives of the higher authorities. However, in areas closely linked to the interests of the residents, such as the distribution of social advantages, "fighting for the defence of rights and the expression of interests" (21) fuels all sorts of demands based on "collective well-being and common interests," (22) the need for "assistance," (23) or requests for "help to survive." (24) In such cases, the Neighbourhood Community is faced with a situation that is not created by pressure from the upper echelons alone, but which has also been shaped by the expectations of residents. Such, for example, was the situation observed during the "Annihilate Cockroaches" campaign.

\section{Demonstrating successes to the upper echelons}

Between 8 November and 9 December 2010, an "Annihilate Cockroaches for a Healthy Beijing" campaign was launched. In the course of its 32-day duration, the Minfengyuan Neighbourhood Community devoted one day -

20. The term "collective household" is used to describe a household whose hukou is no longer registered in the locality of origin, but who has not bought a home in Beijing and who has registered its hukou at the work unit to which it belongs. Most are employees of state-run companies and public institutions or university students.

21. Hu Rong, "Shehui ziben yu chengshi jumin de zhengzhi canyu" (Social capital and political participation of urban residents), Shehuixue yanjiu, No. 5, 2008, pp. 142-159.

22. Yang Min, "Zuowei guojia zhili danyuan de shequ: Dui chengshi shequ jianshe yundong guochengzhong jumin shequ canyu he shequ renzhi de ge'an yanjiu" (Community as state governance unit: A case study on residents' community participation and cognition in the process of community building campaign), Shehuixue yanjiu, No. 4, 2007, pp. 137-164.

23. Zhou Zhijia, "Huanjing baohu, qunti yali haishi liyiboji" (Environmental protection, group pressure, or interests relatedness?), Shehui, No. 1, 2011, pp. 1-34.

24. Wang Xing, "Liyi fenhua yu jumincanyu: Zhuanxingqi zhongguo chengsi jiceng shehui guanli de kunjing jiqi lilun zhuanxiang" (Interests differentiation and residents' participation: The dilemma and theoretical transition of China's urban grass-roots social management), Shehuixe yanjiu, No. 2, 2012, pp. 20-34. 
Table 1 -The different stages of the sixth national census in Beijing

\begin{tabular}{|c|l|l|}
\hline Stages & \multicolumn{1}{|c|}{ Task } & Date in 2010 \\
\hline 1 & Preparation for the work of ordering and updating registers & 31 July - 15 August \\
\hline 2 & Ordering and updating of registers & 15 August - 15 September \\
\hline 3 & Training on filling in the questionnaires & Before 15 October \\
\hline 4 & $\begin{array}{l}\text { Checking the "map of zones for the census" and the "registers of household } \\
\text { heads with family and first names" }\end{array}$ & $15-25$ October \\
\hline 5 & Household surveys & $1-10$ November \\
\hline 6 & Overall checking of data & $11-16$ November \\
\hline 7 & Pooling of data & $16-20$ November \\
\hline 8 & Coding of non-specialist activities & $21-25$ November \\
\hline 9 & Transmission of census data & $\begin{array}{l}\text { After the work of checking the } \\
\text { coding of the non-specialist tasks }\end{array}$ \\
\hline & & \\
\hline
\end{tabular}

5 December - to the actual business of eradicating cockroaches. The operation was successfully carried out by a company hired by the Hygiene and Patriotism Committee of the city of Beijing. For the rest of the time, government departments, beginning with the Subdistrict Office, spent their time drawing up statistics, receiving and transmitting directives and other documents, and writing reports underlining the Office's contribution to the campaign.

The Neighbourhood Community and the Workstation, situated at the bottom of the hierarchy, were therefore the only reported executors of this mission and authors of its successes. There were only 23 days between 17 November, the date on which the Fucai Subdistrict Office transmitted the order to carry out the campaign along with the necessary documents to the Workstations, and 9 December, the date on which the objectives achieved had to be reported to the Office. During this time, the Minfengyuan Residents' Committee and the Workstation were supposed to complete four activities without any additional help: transmit the information to the 2,690 households concerned; receive written demands from households affected by cockroaches and enter their names, addresses, and phone numbers into a computer, and assign them a registration number; visit these households in the company of technicians on an agreed date to give them the necessary pesticides together with instructions for their use, and get them to sign a document confirming their commitment to using them in the prescribed manner; and send tables and figures showing the progress of the operation, on paper and electronically, to the Office three times over the 23 days, before sending a final report once the work was completed.

As usual, the staff of the Neighbourhood Community put great emphasis on the transmission of these figures, tables, and reports as well as any other documents attesting to the work accomplished. On 5 December, when I went with one of the members of the Community, Liu Jinyun, to some of the households concerned, she was very disappointed when she discovered that she had forgotten to bring her camera, and asked me to use my mobile phone to photograph her giving the necessary products to certain heads of household. She then attached these photos to the documents sent to the Office, since the latter would regard them as evidence of the action undertaken. Only something that can be shown to the Office is believed to testify to the action taken by the Neighbourhood Community.

\section{Reassuring the powerful, avoiding the poor: Building on distinctions between residents}

For those working in the Neighbourhood Community, drawing up documents to send to the upper echelons and formatting the successes achieved is a common and familiar type of activity, and one accomplished with little difficulty. However, they fear the specific expectations and demands of residents when the task to be accomplished serves the latter's interests. For example, in the present case, if most of the local households really had gone to the Residents' Committee to request a visit from the technicians to exterminate the cockroaches, it would have represented a very heavy workload.

Faced with just such an awkward situation, when the members of the Neighbourhood Community pasted up notices for the campaign on 17 November, they started with a preliminary selection and distinction: "We'll only paste notices in apartment blocks and not in single-storey houses, since there are cockroaches only in the apartment blocks." (25) The workload was considerably lightened as a result, since Minfengyuan had 96 single-storey houses (pingfang 平房), located fairly far apart, and simply going round to stick up notices would have taken a long time. There were only 19 apartment blocks, however, and having only 19 notices to stick up reduced the workload by more than 80 percent. What's more, households that had not been warned would obviously not come in any great numbers to register with the Residents' Committee. As a result, by the end of the campaign, of the 285 households that had asked for a visit from the technicians, only 10 lived in single-storey homes, creating the impression that those living in this type of housing do not have this type of problem. In actuality, they had been deprived of the right to information about the campaign and were unable to benefit from it.

This type of dissimulation is not always effective, however, and sometimes residents complain. On 8 December, three days after the technicians' visit to people's homes, a resident told the Committee that although he had registered and been told the operation would take place on 5 December, nobody had turned up: "I waited a whole day with my mother; I didn't even go

25. Interview with Liu Jinyun, Beijing, 17 November 2008. 
to market. Result? For you everything is fine, but no one came to my house! Why was this?" (26) When this resident asked for the products needed to eradicate cockroaches, the managers present preferred to dissimulate once more, telling him that all the products had been distributed. This aroused the man's anger and he began to insult them at the top of his voice: "What do you mean nothing is left of the tens of millions the state distributed to kill the cockroaches! You don't even have the means to buy the necessary products? What the hell are you doing on the Committee? You pocket your salary for doing nothing! I don't see any other solution but to take what is needed off your salaries...!" (27) Faced with this reaction, the head of the Committee had no real option. On the one hand he asked the employees present to stay calm: "Don't talk, don't say anything, don't provoke him, let him talk as long as he likes," whilst on the other hand sending a technician to do what was necessary at the man's house - a way of admitting that a mistake had been made and of trying to calm the angry resident. Although the resident called the Beijing mayor's hotline to report the Minfengyuan Residents' Committee's dereliction of duty, and although the town council reported the incident to the Subdistrict Office, the conflict did not really escalate; the Residents' Committee explained itself to the Office and the matter went no further.

The example of the cockroach extermination campaign demonstrates once again the attention given by the members of the Residents' Committee and the Workstation to the data and documents they must transmit to their superiors, and therefore to the means of communication that will enable them to illustrate and testify to the work they have done. Similarly, it shows us the extreme attention paid by the residents to the services and public goods that are distributed and the way in which this, in turn, orients the work of the Committee members. Lastly, the importance attached by the authorities to the prevention of any major incidents can be seen here, hence the instruction not to discuss matters with the angry resident and the choice of a solution that would prevent the conflict from continuing.

Within the general framework of "management by numbers," therefore, the Subdistrict Office and the levels above it mainly control numbers, documents, and tables, and they are above all concerned with the reality that this combined information "shows." On the other hand, the Residents' Committee and the Workstation have to concern themselves with residents' participation and attitudes, because this directly affects the practical implementation of the task in hand. When participation by the residents is limited or is largely indifferent to the form and impact of the action being taken, this may be done in a relatively superficial manner, since the control exercised by numbers leads to all sorts of action that seems self-evident and which is governed by internal rules that now seem tried and tested. Various documentation techniques are then called upon to display the figures and other data that attests to the work done. When the action to be taken affects the interests of residents, their participation appears as the defence of established rights and interests or of the fair distribution of available social welfare benefits, and the work needed proves more difficult, since the tasks to be accomplished cannot disappear behind the compilation of figures and other tables. Such tasks can, however, be reduced after being redefined. Suitable responses are found to the reactions aroused.

\section{Using "figures" to support work reports: The shaping of internal norms}

The analysis developed here of the strategies and techniques used by the staff of the Residents' Committee under study does not contain any moral judgments. As Jacques Revel has said, "The choices of the protagonists are themselves socialised in that they are inseparable from representations of the relational arena, the resources it makes available to them, and the obstacles and constraints it puts before them and which shape the constantly changing configuration within which they must position themselves, then evaluate and exploit their possibilities." (28) The same is true of the documentation techniques, the processing of figures, redefinitions of situations, and the selective answers given by the members of the Residents' Committee and Workstation analysed. These techniques can be found in other administrative bodies and have been the subject of studies. (29) They have nonetheless resulted, in the Residents' Committees, in the shaping of internal norms born of the confrontation between a variety of factors.

\section{Factors that direct the choices of administrators}

As we have seen, amongst the various factors grassroots administrators take into account are the requirements of the higher authorities. During the work of "clarification, simplification, and quantification" (30) needed to fill in tables and documents, they interact constantly with members of the Subdistrict Office and other higher administrative levels in order to identify the compulsory tasks, mistakes they must not make (at a risk of effacing all previous successes), the way in which they must report these actions to the Office (documents to fill in), what needs to be made apparent to the Office (figures to compile), and other important knowledge. This enables them to make the choices necessary to identify and prioritise the tasks to be carried out. They must identify those tasks that cannot be ignored, those for which the least error will not be tolerated (such as incidents occurring during big political meetings, National Day, or the Olympic Games, failures in controlling the birth rate, fire prevention, gas poisoning, etc.). Their knowledge also informs them which documents must not only be completed in detail, but which also require an effort of presentation that call upon more or less official contacts and other resources. This knowledge also helps them identify the activities for which a minimum of information will suffice, since they are everyday, routine tasks (such as, for example, progress made in waste recycling, the cleaning up of public spaces, etc.).

These local officials must also be able to anticipate the response of residents to the various activities to be carried out, understand the nature and intensity of their expectations depending on which area they fall into, identify which demands can be satisfied and which really cannot. Then, before they act and on the basis of this information, they must make the appropriate choices.

Last but certainly not least, they must consider what resources, intermediaries, and contacts they can call upon. It is thanks to such resources

26. Observational Note, Beijing, 8 December, 2008.

27. Idem.

28. Jacques Revel, "L'institution et le social" (The institution and the social), in Bernard Lepetit (ed.), Les formes de l'expérience : Une autre histoire sociale (The forms of experience: Another social history), Paris, Albin Michel, 1995

29. Let us quote, for example, with regard to France: Laurent Thévenot, "L'économie du codage social" (The economy of social codification), Critiques de l'économie politique (Critiques of political economy), No. 23-24, 1983, pp. 188-222; Francis Kramarz, "Déclarer sa profession" (Declaring one's profession), Revue française de sociologie, Vol. 32, No. 1, 1991, pp. 3-27; Christophe Dejours, "Pathologie de la communication" (Pathology of communication), Raisons Pratiques, No. 3, 1992, pp. 52-70. On the tyranny of figures, read, for example Pierre Lascoumes and Patrick Le Galès (eds.), Gouverner par les instruments (Governing by instruments), Paris, Presses de Sciences-Po, 2004.

30. James C. Scott, Seeing Like a State: How Certain Schemes to Improve the Human Condition Have Failed, New Haven, Yale University Press, 1998. 
(premises, equipment, etc.) that the "training given to people who have lost their jobs or who are unemployed, and to workers from other places" that had never been the subject of any previous action and which had therefore previously been invisible, became "visible." The cockroach extermination campaign, in which certain investments were made but which could not quite reach the official objectives, also had to rely in part on mediators such as images, documents, and articles in the press to testify to its success.

Caught between the need to respond to the specific requirements of the higher authorities and the need to take the attitude of residents into account, and because of the relatively limited resources that could be called upon, the members of the Residents' Committee and the Workstation gradually introduced shared internal practices, even if this could not be officially acknowledged or revealed outside their organisation. Their choices are the result of the state of powerlessness in which they had been placed. Perfectly comprehensible, rational considerations resulting from this led to the creation of specific working norms.

\section{From individual conduct to collective norms}

These choices indeed led to the creation of shared norms. Very many of the individual behaviours I was able to observe were adopted by several people. For example, in Minfengyuan in 2008, Liu Jinyun was in charge of hygiene, but also of the handicapped, civil administration, and social security. She also kept the accounts for the Residents' Committee. Faced with such diverse tasks, she adopted solutions that were also diverse. For routine information concerning most of the activities carried out in the sectors she was responsible for, she generally limited herself to "transmitting upwards and that's all, in any case nobody reads all that!" (31) However, when it was a case of more important reports such as the summary she drew up of personal work accomplished in 2008 , she could display an impressive mastery of figures, using them in abundance and giving a detailed quantified account of the objectives achieved. What was at stake in this case was the evaluation of the work accomplished during the year, and the figures presented could not be confusing or incoherent.

The anti-cockroach campaign was a question of hygiene and therefore her responsibility, so she adopted the same attitude here. There were clearly gaps in the documents filled in during the registration of households and the technicians' visits, but she had considered these to be of little importance and had agreed that they should be sent as they were to the Subdistrict Office. "It doesn't matter if we have sometimes forgotten to write down people's name or telephone number. It's partly filled in, that's enough." (32) Her attitude changed, however, when she had to send tables showing the progress of the operation and the results obtained. On this occasion she checked the accuracy and coherence of the figures several times, constantly asking, "Is that right? Have we landed on our feet?" (33) Paying selective attention to the documents transmitted depending on the attention given them by the upper echelons, and paying such intense, almost obsessive attention to the figures was not restricted to Liu Jinyun. The other members of the Workstation shared these tendencies to a greater or lesser degree. Wei Wen, for example, in charge of summarising security-related work in 2008, drew up an impressive battery of figures to demonstrate the efforts made. The same was true of other administrators. Nobody was surprised by the choices and working methods of others, since they seemed self-evident. Similarly, working methods sometimes called for coordination between several administrators, which was effortlessly achieved on the basis of a common understanding and the implementation of shared internal norms.

\section{Conclusion}

It can therefore be seen that Liu Jinyun and the other grassroots administrators in this article adopted a working method that may be characterised as follows: simplifying the work to be done but quantifying the objectives it achieved. These behaviours, accomplished individually to meet requirements issued from above, resulted in a modus operandi specific to the administrators of the Party Committee, the Residents' Committee, and the Workstation under study. They even led to the shaping of shared internal practices and norms that seemed self-evident to them, and which could, if necessary, be named and transmitted.

It was not a question here of informal practices, but of completely formal practices prevailing within a group, an "in-group" to use Alfred Schütz's term, ${ }^{(34)}$ meaning a group formed by people who share not only the same socio-cultural environment and its constraints, a system of interpretation, a stock of knowledge, and practical formulas, but also forms of rationalisation and institutionalisation. The members of an in-group are all confronted with the same familiar situation, even if it is not always detectable from outside. In the present case, the perimeter of validity of the established rules is, in fact, limited to the frontiers of the group concerned even if similar groups have also adopted them.

These rules and practices are therefore quite formal. They emerge from the particular configuration that links those who work within the Neighbourhood Community to the higher administrative and political echelons and to the residents. In return, they provide us with information, doubtless far more than official directives and abstract organisation charts, on the relationships that have been forged in China today between urban administrators at different levels and those they administer, a relationship that, even if it varies according to circumstance, appears secondary in relation to the hierarchical relationships established between the Subdistrict Office and the Neighbourhood Community.

\section{Translated by Élisabeth Guill.}

I Wang Di, PhD candidate in sociology, EHESS - Peking University. Peking University, School of Journalism and Communications (Xinwen yu chuanbo xueyuan), Beijing, 100 871, China (821013w@163.com).

31. Observational Note, Beijing, 10 December, 2008

32. Interview with Liu Jinyun, Beijing, 20 November 2008.

33. Observational Note, Beijing, 20 November - 10 December 2008.

34. Alfred Schütz, "Equality and the Social Meaning Structure of the Social World," in A. Brodersen (ed.), Alfred Schütz, Collected paper II, Studies in social theory, The Hague, Martinus Nijhoff, 1976. 